\title{
Management of Class II Hyperdivergent Mandible by Surgically Altering Occlusal Plane Pattern through Counterclockwise Rotation of Mandible
}

\author{
Balaguhan Balasubramanian ${ }^{1}{ }^{\oplus}$, Neelakandan Ravanasamudram Sundaram ${ }^{2}$, Srinivasan Boovaraghavan $^{3}(\mathbb{0}$, \\ Raja Sekar Gali ${ }^{4}$, Sudhakar Venkatachalapathy ${ }^{5}$, Kirthika Natarajan ${ }^{6} \odot$
}

\begin{abstract}
Aim and objective: To evaluate the facial esthetic of class II hyperdivergent mandible by altering the high mandibular plane angle into an orthognathic mandibular plane angle by counterclockwise (CCW) rotation of the mandible.

Materials and methods: Five patients with class II hyperdivergent mandible were selected for this study. Initially, preorthodontics was done by aligning the teeth. Then, surgically, bilateral sagittal split osteotomy (BSSO) advancement with CCW rotation of mandible with a posterior open bite of $4 \mathrm{~mm}$ was done. Eleven linear and 11 angular measurements were taken. Pre- and postsurgical values were evaluated by composite cephalometric analysis, and the changes in the occlusal plane and facial height were statistically analyzed by using paired $t$-test. Jarabak ratio was calculated for facial height measurements. Further finishing will be done by postsurgical orthodontic procedures to get functional occlusion. Results: Change in occlusion to class I is seen in values of Jarabak ratio and Go-Gn. Jarabak ratio shows an increase in posterior and decreases in anterior facial height. Go-Gn, which implies the CCW movement of the mandible, has reduced the anterior open bite and created a posterior open bite of $4 \mathrm{~mm}$ for the supraeruption of teeth.

Conclusion: BSSO with CCW rotation of mandible with a posterior open bite has conservatively involved in single-jaw surgery, thereby improving the facial esthetics of all the patients taken this study.

Clinical significance: This innovative method of CCW rotation of mandible with open bite mainly prevents the bi-jaw surgery, improves the stability, and gives an esthetically good appearance.

Keywords: BSSO, Class II hyperdivergent mandible, Counterclockwise rotation of mandible, Occlusal plane alteration.

The Journal of Contemporary Dental Practice (2021): 10.5005/jp-journals-10024-3146
\end{abstract}

\section{INTRODUCTION}

Facial appearance is the key factor in interrelationships between human beings and their socio-psychological developments. Therefore, orthognathic surgery has been the objective of correcting skeletal discrepancies as well as altering facial balance, to achieve the esthetic results in patients who have severe disharmony of the jaws. ${ }^{1}$ The general surgical line of treatment for class II malocclusion with hyperdivergent mandible was surgical vertical maxillary impaction and mandibular advancement with genioplasty [bi-jaw surgery combining Le Fort I osteotomy to bring about the maxillary impaction and rotational bilateral sagittal split osteotomy (BSSO) for mandibular advancement combined with/without sliding genioplasty] for further profile enhancement. ${ }^{2}$ Another approach was through Le Fort I osteotomy and augmentation genioplasty. ${ }^{3}$

As discussed by Bruce N Epker in 1993, there is a misconception developed that the counterclockwise (CCW) rotation of the occlusal plane is an unstable procedure; further, he stated that one should randomly alter the occlusal plane angle based on their clinical impression to emphasize that this is the simplest method of correcting the existing functional and esthetic relationship of class II malocclusion with hyperdivergent mandible. ${ }^{4}$

The case selection for class II hyperdivergent mandible was mainly done, based on the lateral cephalometric analysis of upper and lower gonial angle, ramus length, occlusal, and mandibular plane angle of each patient, who were within our parameters. This common deformity encountered by the maxillofacial surgeons
${ }^{1}$ Department of Oral and Maxillofacial Surgery, Karpaga Vinayaga Institute of Dental Sciences, Maduranthakam, Tamil Nadu, India

${ }^{2}$ Department of Oral and Maxillofacial Surgery, Meenakshi Ammal Dental College and Hospital, Maduravoyal, Tamil Nadu, India

${ }^{3}$ Department of Orthodontics and Dentofacial Orthopedics, Meenakshi Ammal Dental College and Hospital, Maduravoyal, Tamil Nadu, India

${ }^{4}$ Department of Oral and Maxillofacial surgery, Narayana Dental College and Hospital, Nellore, Andhra Pradesh, India

${ }^{5}$ Department of Orthodontics and Dentofacial Orthopedics, Adhiparasakthi Dental College and Hospital, Melmaruvathur, Tamil Nadu, India

${ }^{6}$ Department of Conservative Dentistry and Endodontics, Karpaga Vinayaga Institute of Dental Sciences, Maduranthakam, Tamil Nadu, India

Corresponding Author: Balaguhan Balasubramanian, Department of Oral and Maxillofacial Surgery, Karpaga Vinayaga Institute of Dental Sciences, Maduranthakam, Tamil Nadu, India, Phone: +91-9841263109, e-mail:dr.guhan@gmail.com

How to cite this article: Balasubramanian B, Sundaram NR, Boovaraghavan S, et al. Management of Class II Hyperdivergent Mandible by Surgically Altering Occlusal Plane Pattern through Counterclockwise Rotation of Mandible. J Contemp Dent Pract 2021;22(9):1048-1054.

Source of support: Nil

Conflict of interest: None

(c) The Author(s). 2021 Open Access This article is distributed under the terms of the Creative Commons Attribution 4.0 International License (https://creativecommons. org/licenses/by-nc/4.0/), which permits unrestricted use, distribution, and non-commercial reproduction in any medium, provided you give appropriate credit to the original author(s) and the source, provide a link to the Creative Commons license, and indicate if changes were made. The Creative Commons Public Domain Dedication waiver (http://creativecommons.org/publicdomain/zero/1.0/) applies to the data made available in this article, unless otherwise stated. 
was intervened by bi-jaw surgery along with consolidated fixed orthodontics in all three planes of spaces. ${ }^{5}$ But CCW of mandible involving single-jaw surgery was stated as a nonstandardized protocol due to lack in the evaluation of mandibular stability and the amount of rotation. ${ }^{4}$ Further, there is no evidence of studies that state the CCW of the mandible with posterior open bite, which can be compensated with supraeruption of teeth.

Hence, the aim of the study was to manage the patients with class II hyperdivergent mandible by surgically altering occlusal plane pattern through CCW rotation of mandible with a posterior open bite of $4 \mathrm{~mm}$.

\section{Materials and Methods}

\section{Sample}

Five female patients aged between 19 and 22 years were selected in this study with skeletal class II hyperdivergent mandible, and patients were informed briefly about the procedure, and consent to participate in this study was also obtained from the study participants. All patients were selected from the files at the Department of Orthodontics, and surgery was performed at the Department of Maxillofacial Surgery, Karpaga Vinayaga Institute of Dental Sciences, between 2018 and 2020. This prospective study was started after obtaining ethical clearance from the Review Board of Karpaga Vinayaga Institute of Dental Sciences, Chengalpattu.

The cephalograms of patients with high mandibular plane angle (SN-GoGn $33^{\circ}-37^{\circ}$ ) and high lower gonial angle (GoGn-GoN $78^{\circ} \pm 3^{\circ}$ ) were included in the study. Low mandibular plane angle, vertical maxillary excess along with the high plane angle, and syndromic patients were excluded from the study. Cephalometric tracing was repeated with a lag period of 4 weeks by the same operator. The cephalogram was traced using composite analysis.

Eleven linear and angular measurements (composite analysistotal 22) that accurately interpret the facial esthetics evaluation and improvement were further subdivided into the maxillary, mandibular, and maxillomandibular complex. These measurements were analyzed both pre- and postoperatively and compared with the normal value range in the following manner. ${ }^{5}$

\section{Maxilla}

- SNA-The angle between the anterior cranial base (SN) and the NA line.

- ANS to PNS-The length of the maxilla.

- U6-NF-Upper first molar to the nasal floor.

- U1-NF-Upper incisors to the nasal floor.

- N to PNS-Upper posterior facial height.

\section{Mandible}

- Ar-Go-Mandibular ramus length.

- Go-Pg-Mandibular body length.

- L6-MP_Lower first molar to mandibular plane.

- L1-MP_Lower incisor to mandibular plane.

- SNB - The angle between the anterior cranial base (SN) and the NB line.

\section{Maxillomandibular Complex}

- ANB - The angle between the NA and NB lines.

- Gonial angle-The angle between the Go-Gn line and the Go-Ar line.

- Upper gonial angle-The angle between the Go-N line and the Go-Ar line.
- Lower gonial angle-The angle between the Go-Gn line and the Go-N line.

- SN-GoGn-The angle between the SN plane and the Go-Gn line-mandibular plane angle

- Lower facial height-The angle between the ANSXi line and the PmXi line.

- OP-SN-The angle between the cranial base (SN plane) and the occlusal plane.

- OP-FH-The angle between the FH plane and the occlusal plane.

- OP-GoGn-The angle between the mandibular plane (Go-Gn) and the occlusal plane.

- ANS to Gn-Lower anterior facial height.

- Anterior facial height-N-Me

- Posterior facial height-S-Go

\section{Surgical Method}

One maxillofacial surgeon with the orthodontist was involved in the entire treatment, and the cephalometric tracing was carried out by a single operator. For all patients, the presurgical orthodontics and analysis were carried out by model surgery with Erikson's platform, and prefabricated splints were done. During surgery, when BSSO was done, the cut was given distal to the first molar and mesial to the second molar, which acts as a fulcrum for CCW rotation. Once BSSO was done, the prefabricated splint was placed on the planned positions, and intermaxillary stabilizations were carried out. The bony segments were fixed in the condylar resting position, using a single four-hole plate with a gap (KLS MARTIN, Tuttlingen, Germany) on the external oblique ridge. Then, semirigid skeletal fixation is completed followed by the release of intermaxillary fixation. The position of the condyles and desired occlusion position were checked. In the immediate postoperative period, posterior bite using Trasbond Plus from 3M (South Peck Road, Monrovia, California, USA) was maintained in $4 \mathrm{~mm}$ open bite till the accelerated orthodontic movements are started. Once the orthodontic treatment was started, the posterior bite was reduced to $1 \mathrm{~mm}$ per month from the second month at the postsurgical orthodontic phase, and supraeruption of molars was achieved within 5 months of period. No additional orthognathic surgical procedures were performed, and semirigid internal fixation was done in all patients.

The statistical analysis is done to determine the differences between the inclination of occlusal planes and facial proportions with mandibular rotations both pre- and postoperatively (completion of postsurgical orthodontics) using cephalometric values by paired $t$-test $(p<0.05)$.

\section{Results}

Lateral cephalometric analysis was done to evaluate the upper and lower gonial angle, occlusal and mandibular plane angle, ramus length, mandibular body length, and Jarabak ratio.

The results were analyzed using paired $t$-test with the statistical difference of $p$-value $<0.05$ on three bases - maxilla, mandible, and maxillomandibular complex both pre- and postoperatively.

\section{Maxilla (Tables 1 to 3 )}

- SNA-No change in the values.

- ANS to PNS-No change in the values.

- U6-NF-There is a statistically significant increase. 
Table 1: Preoperative measurement of data

\begin{tabular}{|c|c|c|c|c|c|c|c|c|}
\hline & P1 & $P 2$ & P3 & P4 & P5 & Mean & Standard deviation & Normal values \\
\hline \multicolumn{9}{|l|}{ Maxilla } \\
\hline SNA (degree) & 81 & 81 & 80 & 81 & 82 & 81 & 0.707 & $82 \pm 2$ \\
\hline ANS to PNS (mm) & 58.2 & 57.8 & 56 & 58.5 & 59.2 & 57.940 & 1.1992 & $55.2-60.2$ \\
\hline U6-NF (mm) & 24.6 & 24 & 23.8 & 24.2 & 25.1 & 24.340 & 0.5177 & $24.2-28.2$ \\
\hline U1-NF (mm) & 28.9 & 29.2 & 28.6 & 29.6 & 31.8 & 29.620 & 1.2736 & $28.4-32.6$ \\
\hline $\mathrm{N}$ to PNS (mm) & 53.9 & 54.2 & 52.8 & 54.6 & 55.4 & 54.240 & 0.9813 & $52.2-55.6$ \\
\hline \multicolumn{9}{|l|}{ Mandible } \\
\hline Ar-Go (mm) & 45.2 & 45.5 & 44.8 & 46.9 & 48.1 & 46.100 & 1.3693 & $47.8-56.2$ \\
\hline Go-Pg (mm) & 62.0 & 60.9 & 61.6 & 61.4 & 62.8 & 61.74 & 0.713 & $68.5-80.1$ \\
\hline L6-MP (mm) & 33.9 & 35.2 & 34.8 & 34.2 & 33.6 & 34.340 & 0.6542 & $33.2-38.4$ \\
\hline L1-MP (mm) & 43.2 & 44.1 & 43.8 & 41.9 & 40.6 & 42.720 & 1.4550 & $42-45.1$ \\
\hline SNB (degree) & 77 & 76 & 74 & 76 & 75 & 75.60 & 1.140 & $80 \pm 2$ \\
\hline \multicolumn{9}{|l|}{ Maxillomandibular complex } \\
\hline ANB (degree) & 4 & 5 & 6 & 5 & 7 & 5.40 & 1.140 & $2 \pm 2$ \\
\hline Gonial angle (degree) & 138 & 137 & 140 & 137 & 139 & 138.20 & 1.304 & $130 \pm 7$ \\
\hline Upper gonial angle (degree) & 57 & 58 & 61 & 59 & 62 & 59.40 & 2.074 & $50 \pm 5$ \\
\hline Lower gonial angle (degree) & 81 & 79 & 79 & 78 & 77 & 78.80 & 1.483 & $70 \pm 5$ \\
\hline SN-GoGn (degree) & 35 & 35 & 36 & 34 & 36 & 35.20 & 0.837 & 32 \\
\hline Lower facial height (degree) & 45 & 47 & 48 & 47 & 49 & 47.20 & 1.483 & $42.77-49.79$ \\
\hline OP-SN (degree) & 16 & 14 & 17 & 15 & 16 & 15.60 & 1.140 & 14 \\
\hline OP-FH (degree) & 8 & 8 & 9 & 7 & 8 & 8 & 0.707 & $1.1-11.3$ \\
\hline OP-GoGn (degree) & 17 & 16 & 19 & 15 & 18 & 17 & 1.581 & $12-20$ \\
\hline ANS to $\mathrm{Gn}(\mathrm{mm})$ & 74 & 73 & 75 & 74 & 74.5 & 74.10 & 0.742 & $64.8-72.4$ \\
\hline Anterior facial height (mm) & 124 & 120 & 123 & 124 & 126 & 123.4 & 1.959 & $105-120$ \\
\hline Posterior facial height (mm) & 76 & 73 & 72 & 74 & 75 & 74 & 1.414 & $70-85$ \\
\hline Jarabak ratio (\%) & 61 & 61 & 59 & 60 & 56 & 60 & 1 & $62-65$ \\
\hline
\end{tabular}

- U1-NF-There is a minimal increase in the values not statistically significant.

- $\mathrm{N}$ to PNS-There is a minimal increase in the values not statistically significant.

\section{Mandible (Tables 1, 2, and 4)}

- Ar-Go-There is a statistically significant increase.

- Go-Pg-There is a statistically significant increase.

- L6-MP-There is a statistically significant increase.

- L1-MP-There is a minimal increase in the values not statistically significant.

- SNB-There is a statistically significant increase.

\section{Maxillomandibular Complex (Figs 1 and 2) and} (Tables 1, 2, and 5)

There is a statistically significant decrease in the values of:

- ANB

- Gonial angle

- Lower gonial angle

- SN-GoGn

- Lower facial height

- OP-SN

- OP-FH

- ANS to Gn

- Anterior facial height
There is a statistically significant decrease in the values of:

- Posterior facial height

There is no statistically significant difference in the values of:

- Upper gonial angle.

- OP-GoGn.

Jarabak ratio has been calculated for all the patients, and there is a statistically significant increase in the percentage that shows a decrease in facial height of $3.2 \pm 0.2 \mathrm{~mm}$ anteriorly and an increase of $3.7 \pm 0.2 \mathrm{~mm}$ posteriorly, resulting in normodivergent appearance.

Overall, for all the five patients, there is a change in Jarabak ratio values and Go-Gn, which implies that there is an increase in posterior and decrease in anterior facial height added to it Go-Gn that implies that the CCW movement of the mandible has reduced the anterior open bite.

\section{Discussion}

Hyperdivergent skeletal class II malocclusion has always been challenging for orthodontists in both sagittal and vertical directions. If the early diagnosis (i.e., between 10 and 15 yearsgrowth phase) was done for such patients, then high pull headgear, ${ }^{6}$ Herbst appliance, ${ }^{7}$ and van Beek appliance ${ }^{8}$ have been reported to be an effective method. But unfortunately, most patients miss the opportunity for early intervention and become 
Table 2: Postoperative measurement of data

\begin{tabular}{|c|c|c|c|c|c|c|c|c|}
\hline & P1 & $P 2$ & P3 & P4 & P5 & Mean & $\begin{array}{l}\text { Standard } \\
\text { deviation }\end{array}$ & Normal values \\
\hline \multicolumn{9}{|l|}{ Maxilla } \\
\hline SNA (degree) & 81 & 81 & 80 & 81 & 82 & 81 & 0.707 & $82 \pm 2$ \\
\hline ANS to PNS (mm) & 58.2 & 57.8 & 56 & 58.5 & 59.2 & 57.940 & 1.1992 & $55.2-60.2$ \\
\hline U6-NF (mm) & 26.2 & 26.3 & 25.4 & 27.1 & 26.9 & 26.380 & 0.6686 & $24.2-28.2$ \\
\hline U1-NF (mm) & 29.2 & 30.4 & 28.9 & 30.2 & 31.9 & 30.120 & 1.1819 & $28.4-32.6$ \\
\hline $\mathrm{N}$ to PNS (mm) & 53.9 & 54.3 & 52.8 & 54.8 & 55.4 & 54.240 & 0.9813 & $52.2-55.6$ \\
\hline \multicolumn{9}{|l|}{ Mandible } \\
\hline $\operatorname{Ar}-\mathrm{Go}(\mathrm{mm})$ & 45.9 & 46.5 & 46.1 & 48.4 & 49.2 & 47.220 & 1.4856 & $47.8-56.2$ \\
\hline Go-Pg (mm) & 68.3 & 66.1 & 66.9 & 67.9 & 69.8 & 67.800 & 1.4107 & $68.5-80.1$ \\
\hline L6-MP (mm) & 35.4 & 37.4 & 36.2 & 35.9 & 36.1 & 36.200 & 0.7382 & $33.2-38.4$ \\
\hline L1-MP (mm) & 43.8 & 44.9 & 44.6 & 41.9 & 41.2 & 43.280 & 1.6483 & $42-45.1$ \\
\hline SNB (degree) & 79 & 78 & 77 & 80 & 79 & 78.60 & 1.140 & $80 \pm 2$ \\
\hline \multicolumn{9}{|l|}{ Maxillomandibular complex } \\
\hline ANB (degree) & 2 & 3 & 3 & 1 & 3 & 2.40 & 0.894 & $2 \pm 2$ \\
\hline Gonial angle (degree) & 134 & 133 & 134 & 133 & 134 & 133.60 & 0.548 & $130 \pm 7$ \\
\hline Upper gonial angle (degree) & 58 & 58 & 60 & 58 & 60 & 58.80 & 1.095 & $50 \pm 5$ \\
\hline Lower gonial angle (degree) & 76 & 75 & 74 & 75 & 74 & 74.80 & 0.837 & $70 \pm 5$ \\
\hline SN-GoGn (degree) & 30 & 32 & 32 & 30 & 31 & 31.00 & 1.000 & 32 \\
\hline Lower facial height (degree) & 42 & 45 & 44 & 43 & 45 & 43.80 & 1.304 & $42.77-49.79$ \\
\hline OP-SN (degree) & 14 & 13 & 15 & 13 & 14 & 13.80 & 0.837 & 14 \\
\hline OP-FH (degree) & 6 & 7 & 7 & 6 & 5 & 6.20 & 0.837 & $1.1-11.3$ \\
\hline OP-GoGn (degree) & 17 & 15 & 17 & 15 & 17 & 16.20 & 1.095 & $12-20$ \\
\hline ANS to $\mathrm{Gn}(\mathrm{mm})$ & 73 & 70 & 73 & 72 & 71.5 & 71.90 & 1.245 & $64.8-72.4$ \\
\hline Anterior facial height (mm) & 122 & 117 & 120 & 121 & 123 & 120.6 & 2.059 & $105-120$ \\
\hline Posterior facial height (mm) & 80 & 75.5 & 76.5 & 77 & 79.5 & 77.7 & 1.749 & $70-85$ \\
\hline Jarabak ratio (\%) & 66 & 65 & 64 & 64 & 65 & 64.80 & 0.84 & $62-65$ \\
\hline
\end{tabular}

Table 3: Maxillary measurement (pre- and postoperative)

\begin{tabular}{|c|c|c|c|c|c|c|c|c|}
\hline & \multicolumn{5}{|c|}{ Paired differences } & \multirow[b]{3}{*}{$t$} & \multirow[b]{3}{*}{$D F$} & \multirow[b]{3}{*}{ Sig. (two-tailed) } \\
\hline & \multirow[b]{2}{*}{ Mean } & \multirow[b]{2}{*}{ Std. deviation } & \multirow[b]{2}{*}{ Std. error mean } & \multicolumn{2}{|c|}{$\begin{array}{l}95 \% \text { confidence interval of } \\
\text { the difference }\end{array}$} & & & \\
\hline & & & & Lower & Upper & & & \\
\hline $\begin{array}{l}\text { U6-NF-PREOP to U6-NF- } \\
\text { POSTOP }\end{array}$ & -2.0400 & 0.5595 & 0.2502 & -2.7347 & -1.3453 & -8.153 & 4 & 0.001 \\
\hline $\begin{array}{l}\text { U1-NF-PREOP to U1-NF- } \\
\text { POSTOP }\end{array}$ & -0.5000 & 0.4301 & 0.1924 & -1.0341 & 0.0341 & -2.599 & 4 & 0.060 \\
\hline $\begin{array}{l}\text { N-PNS-PREOP to N-PNS- } \\
\text { POSTOP }\end{array}$ & -0.0600 & 0.0894 & 0.0400 & -0.1711 & 0.0511 & -1.500 & 4 & 0.208 \\
\hline
\end{tabular}

the candidates for orthognathic surgery to obtain satisfying profiles and occlusions in the later stage. In the later stage (above 16 years), the most common approach was orthognathic surgical therapy, by repositioning of maxilla and mandible (bi-jaw) sagittally and vertically according to the need of the patient's functional and esthetic prerequisite, which is usually followed by a genioplasty procedure for stability in the lower incisor region and to correct the chin deficiency. Another procedure was distraction osteogenesis for both maxilla and mandible. ${ }^{2,9}$ Finally, CCW rotation of mandible for this type of occlusion is least followed because of its misinterpretation in the literature. Recently, a metaanalysis of 80 studies was done by Supawadee et al. in 2019, on skeletal stability after mandibular CCW rotational advancement for skeletal class II deformity and concluded that it is a stable procedure both horizontally and vertically, but their conclusions show that there should be a standardized measurement protocol for mandibular stability and evaluation of the amount of rotation on esthetic appearance. ${ }^{10}$

In our study, all the cases were selected from the same gender, between 19 and 22 years, and with higher angulation of lower gonial angle $\left(\mathrm{GoGn}-\mathrm{GoN} 78^{\circ} \pm 3^{\circ}\right)$ and mandibular plane angle $\left(\mathrm{SN}-\mathrm{GoGn} 33^{\circ}-37^{\circ}\right.$ ).

The amount of rotation of the mandible is determined by giving a posterior open bite of $4 \mathrm{~mm}$, which is later compensated 
Table 4: Mandibular measurement (pre- and postoperative)

\begin{tabular}{|c|c|c|c|c|c|c|c|c|}
\hline & \multicolumn{5}{|c|}{ Paired differences } & \multirow[b]{3}{*}{$t$} & \multirow[b]{3}{*}{$D F$} & \multirow[b]{3}{*}{ Sig. (two-tailed) } \\
\hline & \multirow[b]{2}{*}{ Mean } & \multirow[b]{2}{*}{ Std. deviation } & \multirow[b]{2}{*}{ Std. error mean } & \multicolumn{2}{|c|}{$\begin{array}{c}95 \% \text { confidence interval of } \\
\text { the difference }\end{array}$} & & & \\
\hline & & & & Lower & Upper & & & \\
\hline $\begin{array}{l}\text { Ar-Go-PREOP to Ar-Go- } \\
\text { POSTOP }\end{array}$ & -1.1200 & 0.3033 & 0.1356 & -1.4966 & -0.7434 & -8.257 & 4 & 0.001 \\
\hline $\begin{array}{l}\text { Go-Pg-PREOP to Go-Pg- } \\
\text { POSTOP }\end{array}$ & -6.0600 & 0.7829 & 0.3501 & -7.0322 & -5.0878 & -17.307 & 4 & 0.000 \\
\hline $\begin{array}{l}\text { L6-MP-PREOP to L6-MP- } \\
\text { POSTOP }\end{array}$ & -1.8600 & 0.4722 & 0.2112 & -2.4463 & -1.2737 & -8.807 & 4 & 0.001 \\
\hline $\begin{array}{l}\text { L1-MP-PREOP to L1-MP- } \\
\text { POSTOP }\end{array}$ & -0.5600 & 0.3286 & 0.1470 & -0.9681 & -0.1519 & -3.810 & 4 & 0.019 \\
\hline $\begin{array}{l}\text { SNB-PREOP to SNB- } \\
\text { POST OP }\end{array}$ & -3.000 & 1.000 & 0.447 & -4.242 & -1.758 & -6.708 & 4 & 0.003 \\
\hline
\end{tabular}

Table 5: Maxillomandibular measurement (pre- and postoperative)

\begin{tabular}{|c|c|c|c|c|c|c|c|c|}
\hline & \multicolumn{5}{|c|}{ Paired differences } & \multirow[b]{3}{*}{$t$} & \multirow[b]{3}{*}{$D F$} & \multirow[b]{3}{*}{ Sig. (two-tailed) } \\
\hline & \multirow[b]{2}{*}{ Mean } & \multirow[b]{2}{*}{ Std. deviation } & \multirow[b]{2}{*}{ Std. error mean } & \multicolumn{2}{|c|}{$\begin{array}{l}\text { 95\% confidence interval of the } \\
\text { difference }\end{array}$} & & & \\
\hline & & & & Lower & Upper & & & \\
\hline ANB-PREOP to ANB-POSTOP & 3.000 & 1.000 & 0.447 & 1.758 & 4.242 & 6.708 & 4 & 0.003 \\
\hline $\begin{array}{l}\text { Gonial angle-PREOP to } \\
\text { gonial angle-POSTOP }\end{array}$ & 4.600 & 0.894 & 0.400 & 3.489 & 5.711 & 11.500 & 4 & 0.000 \\
\hline $\begin{array}{l}\text { Upper gonial angle-PREOP } \\
\text { to upper gonial angle- } \\
\text { POSTOP }\end{array}$ & 0.600 & 1.140 & 0.510 & -0.816 & 2.016 & 1.177 & 4 & 0.305 \\
\hline $\begin{array}{l}\text { Lower gonial angle-PREOP } \\
\text { to POSTOP }\end{array}$ & 4.000 & 1.000 & 0.447 & 2.758 & 5.242 & 8.944 & 4 & 0.001 \\
\hline $\begin{array}{l}\text { SN-GoGn-PREOP to } \\
\text { SN-GoGn-POSTOP }\end{array}$ & 4.200 & 0.837 & 0.374 & 3.161 & 5.239 & 11.225 & 4 & 0.000 \\
\hline $\begin{array}{l}\text { Lower facial height- } \\
\text { PREOP to POSTOP }\end{array}$ & 3.400 & 0.894 & 0.400 & 2.289 & 4.511 & 8.500 & 4 & 0.001 \\
\hline $\begin{array}{l}\text { OP-SN-PREOP to OP- } \\
\text { SN-POSTOP }\end{array}$ & 1.800 & 0.447 & 0.200 & 1.245 & 2.355 & 9.000 & 4 & 0.001 \\
\hline $\begin{array}{l}\text { OP-FH-PREOP to OP- } \\
\text { FH-POSTOP }\end{array}$ & 1.800 & 0.837 & 0.374 & 0.761 & 2.839 & 4.811 & 4 & 0.009 \\
\hline $\begin{array}{l}\text { OP-GoGn-PREOP to } \\
\text { OP-GoGn-POSTOP }\end{array}$ & 0.800 & 0.837 & 0.374 & -0.239 & 1.839 & 2.138 & 4 & 0.099 \\
\hline $\begin{array}{l}\text { ANS-Gn-PREOP to } \\
\text { ANS-Gn-POSTOP }\end{array}$ & 2.200 & 0.837 & 0.374 & 1.161 & 3.239 & 5.880 & 4 & 0.004 \\
\hline $\begin{array}{l}\text { Anterior facial height- } \\
\text { PREOP to POSTOP }\end{array}$ & 2.80 & 0.11 & 0.200 & 2.24 & 3.36 & 14.00 & 4 & 0.000 \\
\hline $\begin{array}{l}\text { Posterior facial height- } \\
\text { PREOP to POSTOP }\end{array}$ & -3.700 & 0.375 & 0.168 & -4.828 & -2.572 & 9.108 & 4 & 0.000 \\
\hline Jarabak ratio & -4.08 & 0.16 & 0.374 & -5.84 & -3.76 & 12.828 & 4 & 0.000 \\
\hline
\end{tabular}

by supraeruption of the upper and lower molar teeth-each arch by $2 \mathrm{~mm}$ (considered to be the permissible measurement for supraeruption). By this procedure, there is an increase in the posterior facial height, ramus, and body length of the mandible.

\section{Maxilla}

In the maxilla, U6 to NF have significant increases in the values due to open bite, given by the bite block that was later compensated by the supraeruption of posterior teeth by $2 \mathrm{~mm}$. Regarding $\mathrm{U} 1$ to $\mathrm{NF}$, there is no statistically significant difference, but there was a minimal increase in the values even though it is not altered, which might be due to the postorthodontic settling effect. N-PNS has no significant change statistically and in SNA and ANS-PNS. No change in the value because the maxilla remains unaltered during surgery.

\section{Mandible}

In mandible, Ar-Go, Go-Pg measurements, and SNB angle had significantly increased by BSSO with CCW rotation and mandibular advancement. ${ }^{11}$ Mandible is CCW rotated and advanced to meet out exact overjet and overbite with a posterior open bite of $4 \mathrm{~mm}$ by the 


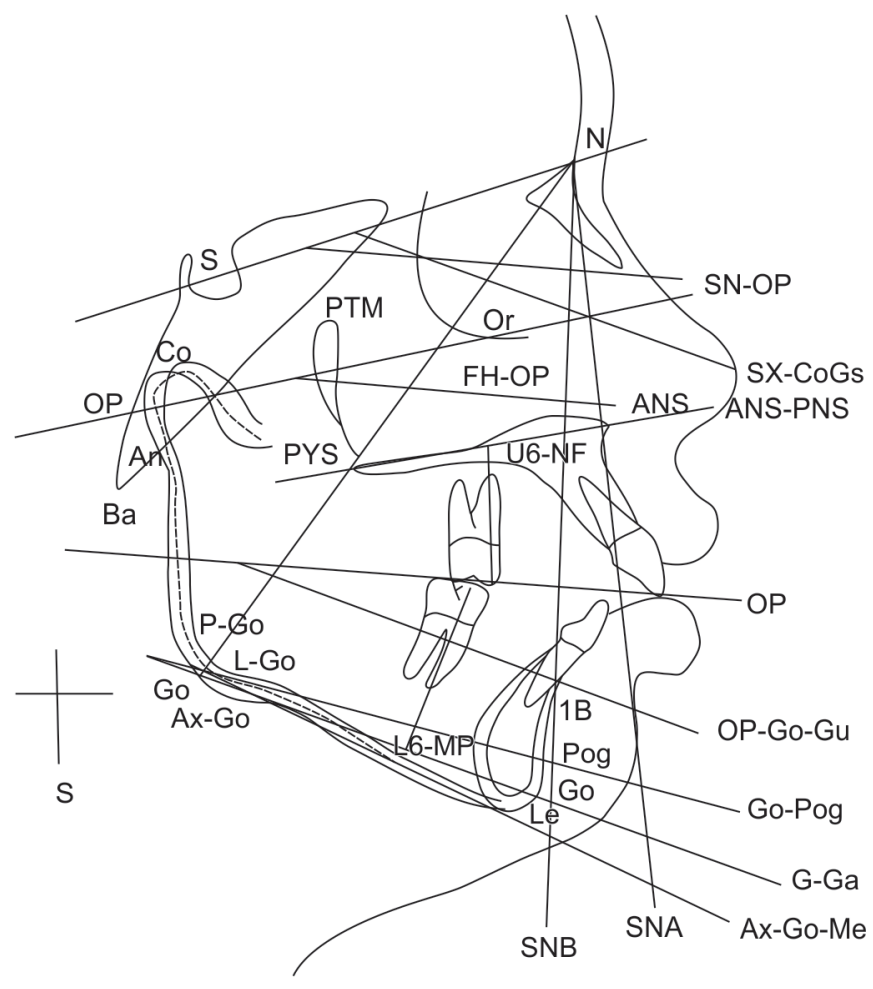

Fig. 1: Pretreatment cephalometric analysis of P4

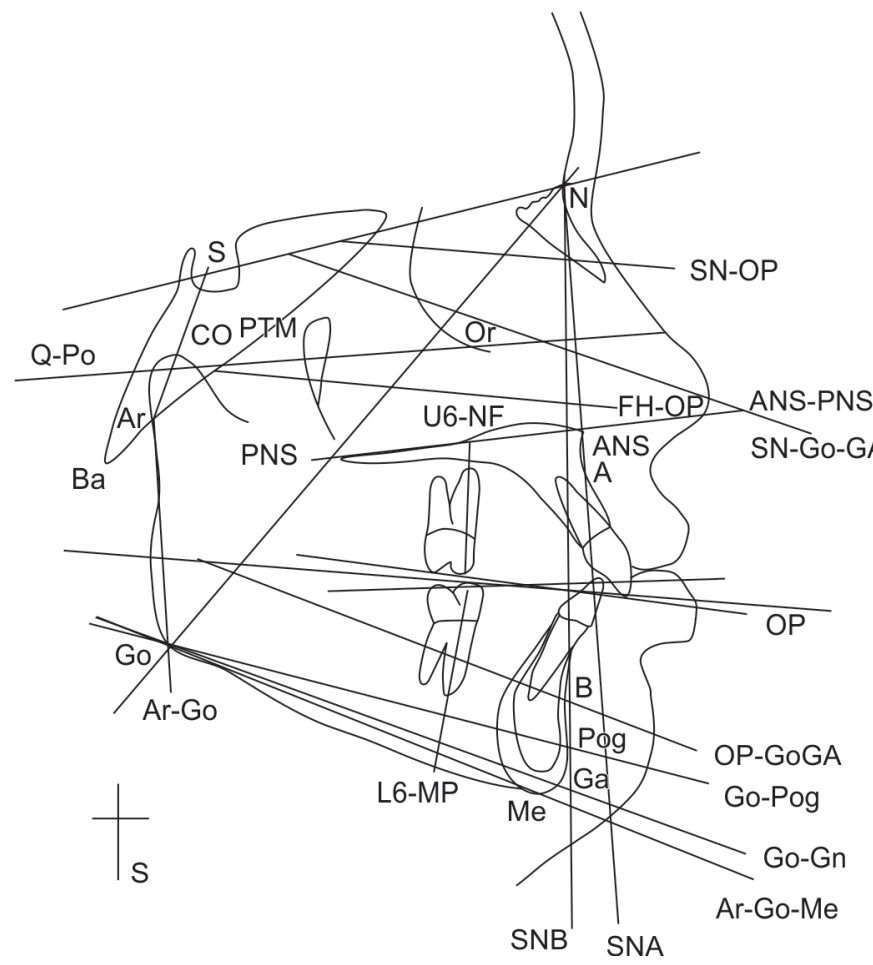

Fig. 2: Posttreatment cephalometric analysis of P4

aid of a prefabricated occlusal splint. Semirigid fixation is carried out with plates and screws by holding the mandible in the new altered position and maintaining the condyles in the rest position. The increase in Go-Pg and SNB indicates the increase in body length, and the increase in Ar-Go shows that the shorter ramus length has been increased to a near-normal value of $47.220 \mathrm{~mm}$ (mean) (normal value-47.8-56.2). L6 to MP $1.86 \mathrm{~mm}$ (mean) is increased due to open bite given as mentioned in the maxillary discussion part. ${ }^{12,13}$ Similarly, in L1 to MP, there is no statistical difference, but minimal increase due to compensatory postorthodontic settling.

\section{Maxillomandibular Complex}

In the maxillomandibular complex, there is a significant decrease in the angles of ANB, gonial angle, lower gonial angle, and lower anterior facial height, as well as a decrease in ANS to $\mathrm{Gn}(\mathrm{mm})$ is due to the result of CCW rotation of the mandible. ${ }^{12}$ When lower gonial angle decreases by $4^{\circ}$ on CCW rotation of mandible (with the help of prefabricated split), there is a decrease in anterior facial height of $3.2 \pm 0.2 \mathrm{~mm}$ and an increase in the posterior facial height of $3.7 \pm 0.2 \mathrm{~mm}$. The significant decrease in the ratio of lower facial height implies that there is an increase in lower posterior facial height and ramal length. Moreover, Jarabak ratio of pre- and postoperative comparison shows an increase in lower posterior facial height and a decrease in anterior facial height. ${ }^{13,14}$ This gives us a clear view that an increase in lower posterior facial height and decreases in anterior height are not only contributed to CCW rotation but also because of the supraeruption of the posterior teeth by $4 \mathrm{~mm}$. Decrease in OP-SN and OP-FH further confirms the clearcut CCW orientation of the occlusal plane, because of the surgery and planned selective orthodontic supraeruption of posteriors. ${ }^{15}$ The untouched maxilla is reflected by an unchanged upper gonial angle with a mild decrease in values. No significant difference is noted in GoGn to occlusal plane; this is because the CCW rotation of the mandibular plane is compensated by the supraeruption of mandibular molars. ${ }^{16}$ As stated by De Oliveira et al in 2016, there was a significant reduction in SN-GoGn, clearly indicating the CCW rotation of the mandibular plane, because of the upward movement of GN and downward movement of Go. ${ }^{17}$

Frey et al. in 2007 have done a similar study involving 127 patients by surgically doing CCW of the mandible with an acrylic splint that was placed in the maxilla. Postoperatively, intermaxillary fixation was done for 8 weeks and removed after that and checked for the stability for 2 years of follow-up. They concluded that there was a late horizontal and vertical relapse that may vary from patient to patient within the physiologic limits. ${ }^{15}$ In our study, the dental occlusal settlement was done after surgery by supraeruption of the teeth by $1 \mathrm{~mm}$ in the interval of 1.5 months postorthodontically, which ultimately lead to the maintenance of stretched muscles to a newer position for 5-6 months and to adaptation of muscles, and thereby we relay that the relapse and skeletal instability will not occur.

Some limitations like gender selection and sample size must be excluded, and further studies must be done without age limit along with other parameters like dental stability, articular disc repositioning, and oropharyngeal airway changes to prove it. Further literatures demonstrate that the main contraindications for CCW rotation of the mandible were the relapse and temporomandibular disorder functional prognosis, which must be studied in the future with our surgical technique.

\section{Conclusion}

It is concluded that BSSO with CCW rotation of the mandible along with posterior open bite followed by the selective supraeruption of the posterior teeth helps in the muscular adaptation, thereby reducing the relapse rate. Finally, increasing the posterior facial height and ramal length drastically improves the facial appearance 
to be more esthetic and conservatively involved in single-jaw surgery instead of bi-jaw surgery.

\section{OrCID}

Balaguhan Balasubramanian (1) https://orcid.org/0000-0002-40080258

Srinivasan Boovaraghavan $\odot$ https://orcid.org/0000-0001-7688-9764 Raja Sekar Gali • https://orcid.org/0000-0002-8055-1608

Sudhakar Venkatachalapathy @ https://orcid.org/0000-0003-19312250

Kirthika Natarajan (1) https://orcid.org/0000-0002-5740-1062

Neelakandan Ravanasamudram Sundaram @ https://orcid.org/00000003-2739-7311

\section{References}

1. Kim B-R, Oh K-M, Cevidanes LHS, et al. Analysis of 3D soft tissue changes after 1- and 2-jaw orthognathic surgery in mandibular prognathism patients. J Oral Maxillofac Surg 2013;71(1):151-261. DOI: 10.1016/j.joms.2012.02.005.

2. Varella AM, Bhat SS, Revankar AV, et al. Orthodontic surgical approach of severe skeletal hyperdivergent Class II malocclusion treated by Le-Fort I osteotomy, BSSO and Genioplast. J Contemp Orthod 2020:4(3):9-15.

3. Khan N, Adeni KM, Parameswaran R, et al. Surgical management of hyperdivergent Class II malocclusion with vertical maxillary excess: a 2-year follow-up. Contemp Clin Dent 2018;9(6):382. DOI: $10.4103 \% 2 F c c d . c c d$ 484_18.

4. Epker BN. Discussion. J Oral Maxillofacial Surg 1993;51(7):740-741. DOI: 10.1016/S0278-2391(10)80411-2.

5. Ardani IGAW, Wicaksono A, Hamid T. The occlusal plane inclination analysis for determining skeletal class III malocclusion diagnosis. CCIDE 2020;12:163-171. DOI: 10.2147\%2FCCIDE.S248983.

6. Burke M, Jacobson A. Vertical changes in high-angle class II, division 1 patients treated with cervical or occipital pull headgear. Am J Orthod Dentofacial Orthop 1992;102(6):501-508. DOI: 10.1016/08895406(92)70066-J.

7. Ruf S, Pancherz $\mathrm{H}$. The effect of Herbst appliance treatment on the mandibular plane angle: a cephalometric roentgenographic study. Am J Orthod Dentofacial Orthop 1996;110(2):225-229. DOI: 10.1016/ s0889-5406(96)70113-0.
8. Bendeus $M$, Hägg $U$, Rabie B. Growth and treatment changes in patients treated with a headgear-activator appliance. Am J Orthod Dentofacial Orthop 2002;121(4):376-384. DOI: 10.1067/ mod.2002.122177.

9. Pinho T, Figueiredo A. Orthodontic-orthognathic surgical treatment in a patient with Class II subdivision malocclusion: occlusal plane alteration. Am J Orthod Dentofacial Orthop 2011;140(5):703-712. DOI: 10.1016/j.ajodo.2010.01.037.

10. Hasprayoon S, Liao Y-F, Hsieh Y-J. Skeletal stability after mandibular counterclockwise rotational advancement for correction of skeletal class ii deformity - a systematic review and meta-analysis. J Evid Based Dental Practice 2019;19(2):156-165. DOI: 10.1016/ j. jebdp.2019.01.008.

11. Stansbury CD, Evans CA, Miloro M, et al. Stability of open bite correction with sagittal split osteotomy and closing rotation of the mandible. J Oral Maxillofac Surg 2010;68(1):149-159. DOI: 10.1016/j. joms.2009.07.105.

12. Esteves LS, Castro V, Prado R, et al. Assessment of skeletal stability after counterclockwise rotation of the maxillomandibular complex in patients with long-face pattern subjected to orthognathic surgery. J Craniofac Surg 2014;25(2):432-436. DOI: 10.1097/ SCS.0000000000000395.

13. Altay Burgaz M, Eraydin F, Diren Esener S, et al. Patient with severe skeletal class II malocclusion: double jaw surgery with multipiece Le fort I. Turk J Orthod 2018;31(3):95-102. DOI: 10.5152/ TurkJOrthod.2018.17039.

14. Hasprayoon S, Ko EWC, Chen YA. Combine the orthodonticorthognathic surgical correction on class II division 2 malocclusion. J Orthod 2017;29(4):212-223. DOI: 10.30036/TJO.201712_29(4). 0003.

15. Frey DR, Hatch JP, Van Sickels JE, et al. Alteration of the mandibular plane during sagittal split advancement: short- and long-term stability. Oral Surg Oral Med Oral Pathol Oral Radiol Endodontol 2007;104(2):160-169. DOI: 10.1016/j.tripleo.2006.12.023.

16. Ruslin M, Hajrah Yusuf AS, Forouzanfar T, et al. One-year stability of the mandibular advancement and counterclockwise rotation for correction of the skeletal class II malocclusion and high mandibular plane angle: dental and skeletal aspect. Biomed J 2021;S2319417021000111. DOI: 10.1016/j.bj.2021.02.005.

17. De Oliveira LB, Reis JMN, Spin-Neto R, et al. Mechanical evaluation of six techniques for stable fixation of the sagittal split osteotomy after counterclockwise mandibular advancement. Br J Oral Maxillofac Surg 2016;54(5):573-578. DOI: 10.1016/j.bjoms.2016.03.002. 